\title{
DOES THE REFUGEES GO BETTER WITH EMPLOYMENT? AN ONLINE SURVEY ABOUT EMPLOYMENT STATUS OF THIRD COUNTRIES REFUGEES IN EUROPE
}

\author{
Hiba MOHAMMAD ${ }^{a *}$, Amira KOBEISSI ${ }^{b}$ \\ ${ }^{a},{ }^{b}$ Bucharest University of Economic Studies, Romania
}

DOI: $10.24818 / \mathrm{IMC} / 2020 / 04.14$

\begin{abstract}
This paper addresses a debatable and challenging issue, which is the employment status of refugees and migrants from third countries in Europe, since Europe is facing an immense refugee flow and the numbers are growing. While refugees are seeking better living conditions, with a secure income and job status, this subject is important to be researched.

Our research shows that the job situation of refugees and asylum seekers in Europe had an impact on European economy and society. The methodology relies on descriptive statistical investigations using primary data,

Data collection was carried out using a questionnaire, distributed among various groups of individuals from Romania and other European countries.

Our results prove that the employment status is rather difficult, due to some factors such as level of education done in home country, last economic status and it can vary from one European country to another.
\end{abstract}

KEYWORDS: asylum seekers, employment, Europe, migrants, refugees.

\section{INTRODUCTION}

In the past few years, the migration and refugee subject has been one of the most debatable issue in the whole world, it is a crucial topic because it has affected millions of people fleeing from their home countries seeking their safety with a hope to obtain a better life.

Taking about the migration and asylum seekers we cannot deny that the Syrian war has been one of the horrifying topics that occupied the whole world, refugees have been forced to leave their houses, jobs, families and countries to start a new life from scratch.

Moreover, Asylum seekers and refugees had to go through all the difficulties in their journey to reach to Europe, but unfortunately millions had passed away before even reaching their country of destination.

Furthermore, many of refugees had different obstacles when reaching to the new home country, one of the most critical subjects was to find work, whether to be employed, or self-employed.

In this paper we will spot the light about the employment status of refugees in Europe, as many of them came with different experiences and backgrounds, in addition to that they had to learn the local language of the country, understand the local culture, in order to integrate faster in the society. Indeed, when we talk about the integration process, we can see that the employment status is a key challenge that affect the integration approach and it can help on the growth of the host country's economy (Poutvaara and Wech, 2016).

The purpose of this paper is to show an evidence on how refugees are dealing with the employment in the European societies, it will give the insight on how the employment status of the refugee can

\footnotetext{
* Corresponding author. E-mail address: Mohammadhiba19@stud.ase.ro
} 
help in his integration process and the establishment of the workforce, due to the skills and the educational background of the refugees that can beneficiary contribute on the economic and social growth of the host country.

Another important factor that can help to faster the refugee's engagement in the labor market is the contribution of the local public authorities and government into the special integration programs that is usually offered to the refugees in order to help them to understand more about the country's culture, regulations, and language in addition that such programs give the refugees the ability to communicate and build a new relation with the local populations.

Therefore, in order to get an overview about the employment situations of the asylum seekers and refugees in Europe, we used a quantitative method in order to obtain the answers based on the refugees experiences and background and to help us understand which European country is offering a better support to refugees that are eager to establish a better life conditions.

Moving on to the next part of the paper, we will be covering the literature review that will be explained below.

\section{LITERATURE REVIEW}

Since the beginning of the Syrian war, refugees and migrants started to flow in bigger numbers to Europe, at least in EU there has been many discussions about the borders control and how the European countries can help the refugees and migrants to integrate faster in the labor market and have an equal chances of employment (Bredgaard and Thomsen, 2018). There is very recent literature on the case of Syrian refugees. Looking at the effects of Turkey's Syrian refugees (Tumen, 2016). Thus, Syrian refugees have been permitted to work since 2016. Approvals in some sectors, such as irrigation, manufacturing, food and other industries (Razzaz, 2017).

Recent statistics on the job status of refugees found that in 2019 the total number of foreign migrants worldwide reached 272 million (3.4\% of the global population), an increase of 51 million since 2010. About half of the migrants live in just 10 countries, with one third coming from only 10 country of origin. As of December 2018, about 456,000 refugees and asylum seekers have been registered, according to the German Federal Jobs Agency (Battisti et al., 2018). Furthermore, when we talk about each specific country in Europe, which opened its borders and welcomed the refugees and supported them in the integration process, one of those countries is Germany, that has been facing different obstacles due to the huge number of refugees and asylum seekers who require financial aid, housing, language courses and integration programs to integrate them in the local market, while in the long run the German economy predict an increase of the net income due to the low skilled labor that can cut down the low skill wages in Germany (Saal and Volkert, 2019).

Thousands of migrants left their home countries searching for a better life conditions in Europe. As the latest literature review on this subject showed that the integration of refugees in the labor market of the host countries had helped the economy of the host countries to rise. It is also well known that the finding job opportunities and getting the refugees and migrants engaged in the labor market is a first step in the integration process. The integration of refugees into the labor market is vital for their own well-being.

It also affects public finances and forms the public's outlook on refugee migration, which in turn has a wide effect on migration. Taking into consideration that refugees came from different backgrounds, professional skills, educational level, and characteristics. Based on these criteria's, we can be able to analyze based on our study, the situation of the refugees and migrants in the European countries.

Although language and professional skills are definitely necessary for the employment of refugees. instability in the labor market, such as a lack of information on the job market in the host country, limited social networks, confusion regarding asylum or residence status, and legal barriers arise. creating new refugee obstacles. Similarly, employees who were unable to the future advantage of recruiting a refugee may be prevented by a lack of funding. 
A number of serious issues that may influence the integration of refugees were studied by various researchers: initial conditions upon arrival (Braun and Dwenger, 2017).

Another example was mentioned about the refugees and migrants in Turkey, as the influx of Syrian refugees is influencing the economy and culture of Turkey from different aspects such as Turkey has provided assistance to Syrian refugees since 2011. Amounting to 1 percent of GDP under temporary security, secondly Syrian refugees have been contributing in the Turkish economic through their labor supply decisions, and their entrepreneurial skills (Esen and Binatl1, 2017).

In the following section we will explaining about the research questions, then we will be introducing the research methods of this paper.

\section{RESEARCH QUESTIONS/ AIMS OF THE RESEARCH}

As mentioned earlier, the objective of our paper is to understand the refugees and migrants' situation in the European countries in terms of the employment status and their access to the labor market.

The first 4 questions were consisting of portfolio of the respondents that includes also the demographic variables such as (nationality, gender, year of birth, current country of stability), other variables were focusing on the educational side such as (level of education completed in the country of origin), and number of years of stability in European countries.

The variables related to the economic status were consisting of employment and income status: such as the economic status of the refugees in the country of origin (Student / employed / self-employed / unemployed), while in the current country of stability we will focus on the respondents that are already employed to serve the purpose of our paper, and income status (Living comfortably on present income / Coping on present income / Finding it difficult on present income).

Other question was asked to understand the difficulties that refugees faced related to finding legal job in the European labor market, and lastly, we included some interesting questions related to current pandemic of Covid-19 and how the pandemic affected the refugees and migrants in terms of employment and income status.

In the following part we will be describing the methodology used in our paper.

\section{RESEARCH METHODS}

In order to respond to our research objectives, we conducted an online survey and distributed it via social media platform as this method is the most appropriate method in this period to collect a quick and relevant responses, as well as to reach a large number of respondents located in different European countries.

To get our results, the research method that has been used to collect the responses was a quantitative method, which consisted of 12 questions to help us understand the economic criteria of the refugees in the European labor market (income, economic Status), the survey was distributed to 500 respondents located in different European countries, while the survey was distributed in two languages which is English and Arabic in order to be more accessible to a larger group of people who will answer to the survey, while the data was collected between May 10th and September 14th that resulted a 500 respondents.

While since this paper only focuses on the legal employment status of refugees and migrants in Europe, we will take the respondents who are already employed, which are 179 respondents out of the total number of 500 respondents.

In the following section we will illustrate the findings and describe the sample. 


\section{FINDINGS AND ANALYSIS}

According to the extracted data, we focused in the first questions about the respondents portfolio including the demographic variables (nationality, gender, year of Birth, country of stability), as we had 179 respondents, that has been divided into 128 Syrians, 25 Palestinians, 14 Lebanese, 8 Iraqis, 2 Libyans, and lastly 1 respondent from Afghanistan and Tunisian nationalities, as you can see below in table 1:

Table 1. Sample distribution of respondent's nationality

\begin{tabular}{|c|c|}
\hline Nationality & Number of Respondents \\
\hline Syrian & 128 \\
\hline Palestinian & 25 \\
\hline Lebanese & 14 \\
\hline Iraqi & 8 \\
\hline Libyan & 2 \\
\hline Tunisian & 1 \\
\hline Afghanistan & 1 \\
\hline
\end{tabular}

Source: adapted from my own online survey

Moving on to the next question, that is the gender, according to our respondents, there were 99 Males respondents and 80 Females respondents, while the third question was about year of birth, our respondents are from different age category which means we were able to cover a wider group of age classes, the answers vary from age 20 years old up to 60 years old, as will be presented in table 2 below:

Table 2. Sample distribution of respondent's age group

\begin{tabular}{|c|c|}
\hline Age Group (YO) & Number of Respondents \\
\hline $20-29$ & 54 \\
\hline $30-39$ & 84 \\
\hline $40-49$ & 37 \\
\hline $50-60$ & 4 \\
\hline
\end{tabular}

Source: adapted from my own online survey

The next question was to understand the refugees education level in their home country, the answers vary from refugees who only finished secondary school (classes 5- 8 ) up to the university degree (Bachelor, Master, PhD), as the respondents answer were as following: 9 respondents finished secondary school, 45 respondents studied the high school, 14 respondents finished professional school (Trainship), and lastly the bigger number was 111 respondents who finished their university in their home country as presented in table 3 below: 
Table 3. Sample distribution of respondent's level of education in home country

\begin{tabular}{|c|c|}
\hline Level of Education & Number of respondents \\
\hline Secondary School & 9 \\
\hline High School & 45 \\
\hline Professional Trainship & 14 \\
\hline University (BA, MA, PhD) & 111 \\
\hline
\end{tabular}

Source: adapted from my own online survey

The fifth question was to identify where the migrants and refugees are located in the European countries, the answers were as follows:

The biggest number of 55 respondents were located in Germany, followed by 53 respondents in Sweden, 40 respondents in Romania, 8 respondents in Turkey and UK, 5 respondents in Belgium, 3 respondents in France, 2 respondents in Italy and Russia, and lastly 1 respondent in Greece, Canada, and Austria, as it will be shown in Table 4 below:

Table 4. Sample distribution of respondent's current country of stability

\begin{tabular}{|c|c|}
\hline Current Country of Stability & Number of Respondents \\
\hline Germany & 55 \\
\hline Sweden & 53 \\
\hline Romania & 40 \\
\hline Turkey & 8 \\
\hline UK & 8 \\
\hline Belgium & 5 \\
\hline France & 3 \\
\hline Italy & 2 \\
\hline Russia & 2 \\
\hline Greece & 1 \\
\hline Canada & 1 \\
\hline Austria & 1 \\
\hline
\end{tabular}

Source: adapted from my own online survey

Talking about the next question, we wanted to find out for how many years the refugees and migrants have been in Europe, the answers were as follows: the highest number of 76 respondents has been in Europe for $3-5$ years, followed by 56 respondents who spent in Europe for 6 - 8 years, 17 respondents has been for $1-2$ years in Europe, 15 respondents have been for more than 10 years in Europe, 12 respondents have been for 9 - 10 years in Europe, and only 3 respondents have been for less than 1 year in Europe.

Moving on to the next question which is the most important one in our research, we asked the refugees about their employment status in their country of origin in order to identify their employment background, answers were as follows: 98 respondents were employed in their country of origin, while 55 respondents were students, 24 respondents were self-employed and only 2 respondents were unemployed, as it will be shown in table 5 below: 
Table 5. Sample distribution of employment status of respondents in country of origin

\begin{tabular}{|c|c|}
\hline Employment Status & Number of Respondents \\
\hline Employed & 98 \\
\hline Student & 55 \\
\hline Self-employed & 24 \\
\hline Unemployed & 2 \\
\hline
\end{tabular}

Source: adapted from my own online survey

Moving on to the next question, that is about the current income status of the refugees, the answers were as follows: 89 respondents are coping on present income, 66 respondents are living comfortably on present income, 20 respondents are finding it difficult on present income, 4 respondents are finding it very difficult on present income.

The next questions are focused on the current situation of Covid-19 pandemic and how it is affecting the refugees in terms of employment and income, the responses were as follows in terms of employment: 66 respondents are moderately affected, 89 respondents are not affected at all, and 24 respondents are strongly affected. while, the effect of Covid-19 in terms of the income status was as follows: 69 moderately affected, 75 not affected at all, 35 strongly affected (Cimpoeru, et al., 2020). The results will be presented in table 6 below:

Table 6. Sample distribution of employment and income status

\begin{tabular}{|c|c|c|}
\hline & Employment Status & Income Status \\
\hline Moderately Affected & 66 & 69 \\
\hline Not Affected at All & 89 & 75 \\
\hline Strongly Affected & 24 & 35 \\
\hline
\end{tabular}

Source: adapted from my own online survey

The last section we will be presenting the conclusion of this paper.

\section{CONCLUSION}

To summarize our work based on the results we got, it is very important to take into consideration that each European country integrated the refugees and migrants in different way, some of them provided financial aid to the refugees and migrants until they get employed, others are supporting only in the beginning of the refugee's stay, while other countries are providing some special integration programs that can help the refugees and asylum seekers to learn the local language, understand the country's regulation and culture and get more chances to be integrated faster in the society and the labor market, of course all the results gathered were based on an online survey which was distributed in different social media platforms, while people were from different age groups, therefore in order to get more accurate results we could do use a qualitative analysis method such as doing interviews to gather more details about the experience of the refugees and migrants in order to highlight the difficulties that the migrants and refugees faced, in order to bring more specific solutions to the responsible parties in order to create a sustainable economic growth from the contribution of the manpower of the refugees and how they can contribute with their knowledge and experiences to serve their hosted societies. 


\section{REFERENCES}

Braun, S. \& Dwenger, N. (2017). The local environment shapes refugee integration: Evidence from post-war Germany. University of Saint Andrews, School of Economics and Finance, St Andrews, 2017. Discussion Paper no. 1711. Retrieved from https://www.standrews.ac.uk/ wwwecon/repec files/4/1711.pdf.

Battisti, M., Giesing, Y. \& Laurentsyeva, N. (2018). Can job search assistance improve the labour market integration for refugees? evidence from a field experiment. St. Louis: Federal Reserve Bank of St Louis. Retrieved from https://search-proquest-com.am.enformation.ro/docview/2189114704?accountid=136549.

Bredgaard, T. \& Thomsen, T., L. (2018). Integration of refugees on the danish labor market 1. Nordic Journal of Working Life Studies, 8(S4), 7-26. doi: https://doi.org/10.18291/njwls.v8iS4.111161. Retrieved August 14, 2020, from https://searchproquest-com.am.e-nformation.ro/docview/2155673765?accountid=136549.

Cimpoeru, S., Roman, M., Kobeissi, A. \& Mohammad Heba, 2020. How are European Migrants from the MENA Countries Affected by COVID-19? Insights from an Online Survey, Journal of Social and Economic Statistics, Sciendo, 9(1), August, 128-143,.

Esen, O. \& Binatl1, A., O. (2017). The impact of Syrian refugees on the Turkish economy: Regional labour market effects. Social Sciences, 6(4), 129. doi: http://dx.doi.org.am.e-nforma tion.ro/10.3390/socsci6040129.

Poutvaara, P. \& Wech, D. (2016). Integrating Refugees into the Labor Market - a Comparison of Europe and The United States. DICE Report, 14(4), 32-43. Retrieved August 13, 2020, from https://search-proquest-com.am.enformation.ro/docview/1873953884?accountid=136549.

Razzaz, S. (2017). A challenging market becomes more challenging: Jordanian workers, migrant workers, and refugees. International Labour Organization, Beirut, Jordan: ILO Regional Office for Arab States. Retrieved from https://www.ilo.org/wcmsp5/groups/public/---arabstates/---robeirut/documents/publication/wcms_556931.pdf

Saal, M. \& Volkert, J. (2019). Labor market integration of refugees in Germany: employers' experiences and consequences. Ekonomski Vjesnik, 32(2), 425-438. Retrieved July 17, 2020, from https://search-proquest-com.am.e-nformation.ro/docview/2335111403?accountid=1365 49.

Tumen, S. (2016). The economic impact of Syrian refugees on host countries: quasi-experimental evidence from Turkey. American Economic Review, 106(5), 456-460. 